\title{
Paideusis
}

\section{On Taking Experts' Word for Things: Disagreeing with Battersby}

\section{Roland Case}

Volume 6, Number 2, 1993

URI: https://id.erudit.org/iderudit/1073305ar

DOI: https://doi.org/10.7202/1073305ar

See table of contents

Publisher(s)

Canadian Philosophy of Education Society

ISSN

0838-4517 (print)

1916-0348 (digital)

Explore this journal

Cite this article

Case, R. (1993). On Taking Experts' Word for Things: Disagreeing with Battersby. Paideusis, 6(2), 17-21. https://doi.org/10.7202/1073305ar

(C) Roland Case, 1993

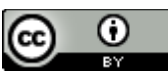

This document is protected by copyright law. Use of the services of Erudit (including reproduction) is subject to its terms and conditions, which can be viewed online.

https://apropos.erudit.org/en/users/policy-on-use/
This article is disseminated and preserved by Érudit.

Érudit is a non-profit inter-university consortium of the Université de Montréal, Université Laval, and the Université du Québec à Montréal. Its mission is to promote and disseminate research.

https://www.erudit.org/en/ 


\section{On Taking Experts' Word for Things: Disagreeing with Battersby}

\section{Roland Case, Simon Fraser University}

Mark Battersby has written a thought-provoking paper on an interesting topic. I have taught several courses on critical thinking and have long had a vague uneasiness about the adequacy of my handling of appeals to authority. Battersby's paper has helped clarify the causes of my uneasiness. In retrospect, I realize that I had adopted the criteria set out in what Battersby calls the "traditional analysis" of appeals to authority because virtually every book that treated the notion offered a similar account. While this uniformity of treatment constitutes-to use Battersby's terms, "consensus in the discipline", he has shown why this consensus about the traditional approach is unwarranted. It is somewhat ironic that I would adopt on appeal to authority incomplete standards for assessing appeals to authority. But I have learned my lesson about taking experts' word for things, promising never again, at least in regard to standards for assessing appeals to authority, to be in what Battersby calls a position of "acute epistemic dependence." In this vein, I propose to assess the arguments about appeals to authority presented by the expert we have just read.

While Battersby raises important concerns about the adequacy of the traditional approach, the model for assessing appeals to authority outlined in the closing pages of his paper does not take us very far in resolving these concerns. In my response, I will consider the two main changes embodied in his proposal and (what I see to be) the confusions that belie them. Before that, let me list some of the very helpful points made in Battersby's paper.

There are at least five observations that strike me as particularly instructive.

1. In most general terms, Battersby has profitably drawn our attention to the need for educators to reassess both the criteria we offer students for assessing appeals to authority and the extent of our reliance on these appeals in our teaching.

2. More specifically, Battersby focuses attention on the importance when assessing authorities of considering whether there are grounds to suspect that other, equally credible experts would disagree with the authority at hand. Before we can have adequate reason to accept expert claims, we need to be able to trust that their claims would withstand the scrutiny of a community of experts in that field.

3. Battersby rightly has reservations about the role of "degree of eminence in the field" as a criterion for assessing authorities. After all, is it rational to prefer Robert Ennis' conception of critical thinking over John McPeck's merely because Ennis sits on more "blue ribbon" committees than does McPeck?

4. Perhaps because of my own thoughtlessness, I had not appreciated until reading Battersby's paper the ways in which assessment of the credibility of both the claim and the spokesperson can profitably be considered in tandem when deciding whether or not to accept a particular view.

5. And, finally, although not explicitly addressed by Battersby, his paper is cause to consider the need for greater explication of a number of key factors 
associated with appeals to authority. Two of these factors readily come to mind. First, in what sorts of predicaments is it reasonable to take an expert's word for things? Second, what qualifies someone as an authority in a field? For example, if I have an ethical problem concerning a teaching situation, should I go to a priest, a philosopher, or a respected educator? Similarly, are cognitive psychologists and/or philosophers to be taken as authorities on critical thinking?

Now, let me turn to some concerns about Battersby's alternative account. As I see it, he recommends two major changes to the traditional approach to assessing appeals to authority. First, he proposes that we supplement the recognized ad hominem considerations articulated in the traditional approach with considerations dealing directly with the justification for the expert's position. For example, in addition to asking whether a claim falls within an expert's area of competence and whether there are grounds for suspecting the expert's objectivity, we should also explore the reasons for the expert's position and reasons for rejecting alternative positions. In short, when dealing with appeals to authority, Battersby asks us to assess both the credibility of the speaker and the credibility of the position.

Second, Battersby recommends adopting a taxonomy of considerations that would do justice to what he regards as relevantly different types of appeals to authority. Battersby invites us to distinguish "general" claims (i.e., claims that essentially are reports of the accepted beliefs within a field of inquiry) from "particular" claims (i.e., claims based largely on the individual expert's judgement). Further, he invites us to distinguish expert claims arising from fields of inquiry characterized by a high degree of consensus about what is known (he calls these fields of inquiry "bomogeneous disciplines") from those arising from fields with a low degree of consensus (what he calls "fractured disciplines').

In my view, both dimensions of Battersby's account of the justification of appeals to authority-namely, adding considerations dealing with the credibility of the position and establishing a taxonomy of considerations-are misplaced because they are peripheral to the real problems that motivate them.

The recommendation to add supplementary criteria dealing with the credibility of the position is misplaced because it is based on a misconception of appeals to authority. Battersby mistakenly equates assessment of appeals to authority with assessment of claims supplied by experts. ${ }^{1}$ I think that we should distinguish assessing the claims that happen to originate from experts from assessing the credibility of experts. If we do not make this distinction, we confuse the source of a claim with its warrant. Accepting a claim made by an expert is an appeal to authority only if the warrant for our belief is the credibility of the expert. If we accept the expert's claim because of the credibility of the position, then we have not resorted to "an appeal to authority." We have not simply taken the expert's word for it. As traditionally understood, appeals to authority arise when it is not feasible to assess the credibility of the claim directly. This explains why, as Battersby notes, the traditional approach to appeals to authority relies on ad hominem considerations.

We can come to understand the roots of this confusion of justified appeals to authority with justified claims made by experts by reminding ourselves of Battersby's concern with students' excessive reliance on experts. The traditional approach appears to Battersby to be inconsistent with the spirit of the 
critical thinking movement which, presumably, arose as an "antidote to students' all-too-willing acceptance of the authoritative pronouncements of teachers and textbooks." Notice that his complaint is not that the traditional account of the criteria for assessing appeals to authority is inadequate, but, rather, that students' reliance on so-called experts may be unjustified and excessive-students appear "all-too-willing" to take experts' words for things instead of assessing directly the credibility of the claims. At issue here are the conditions under which is it justifiable for students to resort to an appeal to authority, not the standards used once that resort is warranted. While I will not presume to explicate the conditions under which it would be rational to resort to appeals to authority, I will suggest a few occasions. An obvious occasion occurs when it is impossible to assess directly the credibility of the position. Clearly, if faced with a need to form an opinion, it would be irrational not to consider whether there are grounds for suspecting the credibility of the purported expert. While meeting these credibility conditions does not "prove" the veracity of the position, they merely confirm that there are no obvious reasons for doubting the expert's word. This type of assessment is better than nothing and, in some cases, it is the best that we can hope for. A particularly relevant educational instance of a justified appeal to authority arises when students do not possess the requisite epistemic background to assess the adequacy of the evidence with sufficient rigour.

Also, appeals to authority may be reasonable even when it is not impossible, but merely undesireable, to assess directly the evidence for a position. It may, for example, be extremely costly in terms of time, effort, or money to assess a position. An interesting educational instance of this situation arises because of what might be called the educational opportunity costs of allowing appeals to authority. Assessing claims takes time. Given that there are many controversial issues requiring students' critical attention, it may be reasonable to accept noncontroversial claims, claims about which there is considerable consensus on the basis of appeal to authority. This would allow more opportunities for students to assess for themselves issues that are controversial. On the other hand, if we expect students to accept an enormous body of "facts" simply on their teachers' authority, we will assuredly fail to promote students' dispositions to critically examine their beliefs.

To conclude this point, answering Battersby's concerns about unjustified reliance on appeals to authority does not require adding considerations dealing with the credibility of the position. ${ }^{2}$ What we need is a more complete explication of the conditions that legitimate resort to appeals to authority in the first place.

The second of Battersby's proposed changes to the traditional approach-a taxonomy of kinds of appeals to authority-is predicated on distinctions he draws between "general" and "particular" judgements and between "homogeneous" and "fractured" disciplines. To my mind, both pairs of distinctions are problematic and unhelpful. I will have little to say about the latter pair except that it seems largely irrelevant whether a claim originates from a fractured or a homogeneous field of inquiry; the more relevant factor is whether or not the claim in question is disputed by experts who have studied the issue. This "agreement-among-the-experts" factor is apparently captured in the distinction between "particular" and "general" judgements. 
From the examples Battersby provides, the general or particular nature of a judgement might appear to depend on the breadth of the matters being explicated. The theory of stress, the nature of the solar system, and the causes of cancer are cited as instances of general judgements; an opinion on why a specific bridge collapsed is an example of a particular judgement. However, on further reading, it is the breadth of the agreement about the veracity of the claim that distinguishes general from particular judgements. When making general judgements, experts report on the "confirmed" views in their field. They present the shared "wisdom of the discipline." The expert functions as a "representative of her discipline," whereas with particular judgements, experts offer views that have not been confirmed by consensual opinion. In these latter cases, we are relying on the "expert's individual expertise" and "her personal views" (emphasis added).

Given this interpretation of the distinction, it is not clear that general claims are appropriate sources of appeals to authority as traditionally defined. There is a subtle but not insignificant difference between a claim that is the confirmed or consensual view and a claim that would be confirmed or receive consensus if considered by open-minded, qualified experts. Obviously, if there is actual consensus about a claim, we would not need to assess the credibility of an individual authority to justify accepting the claim. We would appeal to the authority of the "community of scholars." In these cases, we would look for evidence that all experts who studied the issue had confirmed the uncontroversial nature of the claim. However, the "traditional analysis" offers considerations that assess the credibility of individual authorities. This suggests that these criteria should not be presumed to apply where there exists general consensus about a claim. The traditional analysis-that is, an appeal to (individual) authority-applies either where there is, as yet, no indication of a consensus (for example, claims involving application of expertise to unique situations), or where there is evidence of disagreement among so-called experts. Neither of these cases fall within Battersby's definition of "general" judgements. For this reason, I find the rationale for Battersby's taxonomy unconvincing.

Although I disagree with Battersby's conclusions, I think he has uncovered important inadequacies in the traditional analysis. First, the relevant consideration for assessing disputes among authorities, at least as reported by Battersby, is too narrow. We should not ask whether or not the experts in an area of knowledge agree about the claim, but ask the more inclusive question of whether there is cause to suspect that other, equally credible experts might disagree with this expert. This revision would allow us to include in our assessment of expert claims, those claims that are as yet unconsidered by the community of experts.

Furthermore, what can be said about those situations where there are disputes among experts? If ex hypothesi, when appealing to authority, we cannot consider directly the evidence for the competing claims (otherwise we would not be taking the expert's word for it), are there no grounds for rating the relative credibility of apparently impartial experts who disagree? Or is it the case, as Battersby claims, that the traditional analysis "cannot tolerate disagreement among experts because it provides virtually no method of adjudication"? I think there are additional grounds connected with the reputation of experts. For example, if I could not assess directly the evidence for a particular claim, it 
would be appropriate for me to consider the competing authorities' views on other matters and assess whether there were reasons for deciding that one authority's view of the world coincided more closely with my own view of the world. Thus, the reputation of the expert is not limited to eminence in the field but includes respect in the eyes of the person considering the appeal. This qualification is particularly relevant in those areas that Battersby calls "valueladen disciplines." For example, since I know and respect many of Stephen Lewis' views on issues, I would have grounds to adopt on the basis of his authority a position on a political situation in the face of disagreements with, say, Brian Mulroney for whom I have less respect. In other words, the appellant's relative degree of respect for the disputing experts is a relevant factor. Contrary to Battersby's claim, there are considera- tions-admittedly not always compelling-for rationally adjudicating between competing authority claims.

To conclude, while I am very grateful for Battersby's help in exposing the limits of the traditional treatment given authority claims in critical thinking texts, I am less impressed with his own recommendations on how to redress these inadequacies.

\section{Notes}

${ }^{1}$ In his opening sentence, Battersby states that much of our understanding of the world is based on the "authoritative pronouncements of experts" and, later in that paragraph, he refers to our understanding of the world being "grounded on information supplied and warranted by experts." He implies that these two statements are roughly equivalent and that they attest to the magnitude of our reliance on "'appeals to authority."

${ }^{2}$ There is a strong case to be made for a joint assessment of the credibility of both the position and the speaker whenever evidence for and against the position is inconclusive. 